\title{
The effect of norepinephrine on tonic immobility in chickens
}

\author{
RICHARD W. THOMPSON and SHERRY JOSEPH \\ Western Washington University, Bellingham, Washington 98225
}

\begin{abstract}
Cockerel chicks, habituated to the tonic immobility (TI) induction procedure, were tested for TI duration following no injection or injection of saline or $.25, .5$, or $1.0 \mathrm{mg} / \mathrm{kg}$ of norepinephrine. Results indicated that TI duration was an increasing function of norepinephrine dosage level.
\end{abstract}

Tonic immobility (TI), or animal hypnosis, is characterized by profound behavioral inhibition and is typically brought about by prolonged restraint of the animal. The behavior has been hypothesized to be a result of fear and the activity of the sympathetic nervous system has been implicated. For example, it has been found that TI duration is increased by prior treatment with epinephrine (Braud \& Ginsburg, 1973; Thompson, Scuderi, \& Boren, 1977). Attempts to show a similar effect of norepinephrine have been unsuccessful (Thompson, Scuderi, $\&$ Boren, Note 1). However, the dosage levels of norepinephrine used in the Thompson et al. experiments were quite low $(.05$ to $.2 \mathrm{mg} / \mathrm{kg})$. The present experiment investigated the effect of norepinephrine on TI duration using dosage levels comparable to the dosages of epinephrine which have been found to be effective.

\section{METHOD}

\section{Subjects}

Fifty White Leghorn cockerel chicks, obtained from a local hatchery at 1 day of age, were maintained in a standard commercial brooder with food and water constantly available. The birds were exposed to $12 \mathrm{~h}$ of artificial light each day.

\section{Apparatus and Procedure}

To reduce the duration of TI, starting on the 6th posthatch day and continuing for 5 days, birds were given three TI inductions each day, the bird being permitted to stay down no longer than $90 \mathrm{sec}$. There was at least $15 \mathrm{~min}$ between inductions. On the 11th posthatch day, pairs of birds were haphazardly selected from the brooder, weighed, and either given no injection or injected IP with saline or $.25, .5$, or $1.0 \mathrm{mg} / \mathrm{kg}$ of norepinephrine (DL-Arterenol, hydrochloride, Calbiochem, La Jolla, California). The volume injected was $1 \mathrm{cc} / \mathrm{kg}$. The birds were placed in a holding box for $15 \mathrm{~min}$ and then tested for duration of TI.

Testing consisted of removing each bird from the box, holding it upright on a table for $15 \mathrm{sec}$, rapidly turning it on its side and holding it down for $15 \mathrm{sec}$, and gently releasing it. The response was timed by a stopwatch, from release until spontaneous righting occurred or $900 \mathrm{sec}$ had elapsed. If a bird failed to stay down for at least $5 \mathrm{sec}$, inductions were repeated until the bird stayed down for $5 \mathrm{sec}$ or five inductions had been given. Birds failing to show $\mathrm{TI}$ of at least $5 \mathrm{sec}$ on the fifth induction were given a score of zero.

\section{RESULTS AND DISCUSSION}

Mean durations of TI for all groups are presented in Figure 1. The increase in TI duration as a function of dosage level seen in this figure was found to be statistically reliable $[\mathrm{F}(4,45)=10.10, \mathrm{p}<.01]$.

These data are consistent with previous findings by Braud and Ginsburg (1973) and Thompson et al. (1977) indicating that increased adrenergic (sympathetic) stimulation prolongs the duration of TI. Conversely, it would be expected that blockage of adrenergic stimulation would reduce the duration of TI. However, Thompson (1977), using two alpha-adrenergic blockers (dihydroergotamine and phenoxybenzamine), failed to find any effect of these drugs on TI duration in chickens. Perhaps the increased duration of TI as a result of adrenergic stimulation is primarily a function of stimulation of beta receptors. It should be noted, however, that norepinephrine is thought to stimulate primarily alpha receptors.

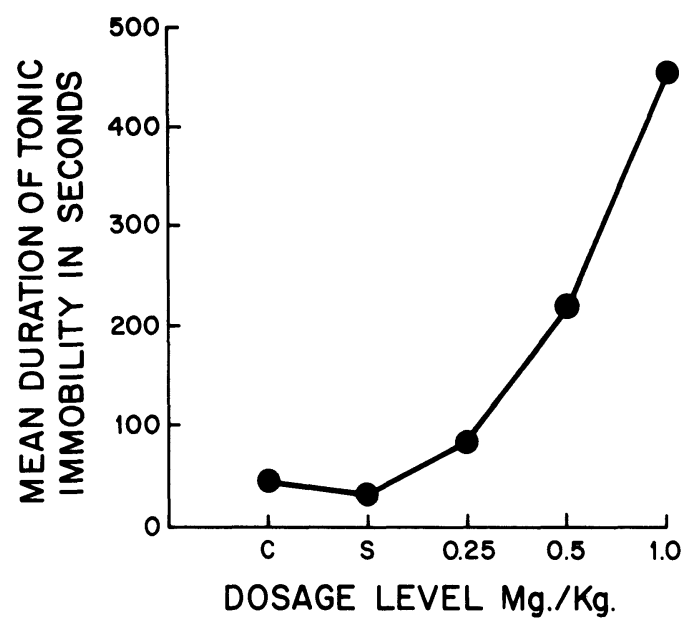

Figure 1. Dose-response curve for norepinephrine and tonic immobility duration in seconds. $C$ is the noninjected and $S$ is the saline-injected control group. 


\section{REFERENCE NOTE}

1. Thompson, R. W., Scuderi, R., \& Boren, J. The effect of the catecholamines on tonic immobility (animal hypnosis) in chickens. Paper presented at the meetings of the Rocky Mountain Psychological Association, Denver, Colorado, May 1974.

\section{REFERENCES}

BRAUD, W. G., \& GinsBURG, R. J. Effect of administration of adrenalin on immobility reaction in domestic fowl. Journal of Comparative and Physiological Psychology, 1973, 83, 124-127.

Thompson, R. W. A central cholinergic inhibitory system as a basis for tonic immobility in chickens. Psychological Record, 1977, 27, Special Issue, 109-121.

Thompson, R. W., Scuderi, R., \& Boren, J. The effect of epinephrine on tonic immobility (animal hypnosis) in chickens. Bulletin of the Psychonomic Society, 1977, 9, 409-410.

(Received for publication April 18, 1978.) 